\title{
Teaching Practice and Exploration on "Automatic Control Theory" in Complete Credit System
}

\author{
Wu Jianzhen ${ }^{1}$, Li Hongqin ${ }^{1}$, Wang Raofen ${ }^{1}$ \\ School of Electronic and Electrical Engineering, Shanghai University of Engineering Science, Shanghai ${ }^{1}$
}

\begin{abstract}
Due to the changes from academic year credit system to complete credit system, the audience in the class is no longer at the same grade and from the same major. "Automatic Control Theory" is an important specialized course for students in major of automation and electrical engineering. In this paper, we discuss how to conduct effective teaching activities from the aspects of students' course selection conditions, class size, teaching reform methods to motivate students' learning interest and improve their learning outcomes in complete credit system.
\end{abstract}

Keywords: Complete Credit System, Automatic Control Theory, Teaching Methods, Teaching Feedback.

\section{INTRODUCTION}

Students are entitled to little freedom to choose when to Table 1 shows the class hours distribution for each chapter learn a course and choose which teacher's class to attend before and after the class hour's reduction. In this paper, in academic year credit system. All students in a natural we will discuss how to operate this course and teaching class will learn the same course in the same period and reforms with less class hours to improve the teaching listen to the same teacher. It can't consider the learning effect of "Automatic Control Theory" curriculum in the differences and learning ability between different students. complete credit environment.

Students can't take the initiative to select their teachers The rest of the paper is arranged as follows. Section 2 who will fit their learning style better. Some students did analysis of how to setup course select pre-conditions, how not lay a solid foundation of a course or did not pass the to arrange the students or limit the number of students in examination, but the next course based on the theory one class to create better conditions for higher learning learned in this course will not postpone the schedule only outcomes from the perspective of student course selection. for his consideration.

Thus, student's academic management is in a passive state which is not conducive to the cultivation of high-quality students. On the contrary, complete credit system fully reflects the student's choice initiative which measures student's academic performance through credits [1-4]. If students achieve minimum number of credits required for graduation, they can apply for a diploma. It breaks the concept of natural classes. Each student can actively manage their own credits and arrange courses of each semester according to the strength of their learning ability. The years required for graduation will be no longer same.

"Automatic Control Theory" is an important specialized basic course for students in major of automation and electrical engineering. It is the basic theory for the following courses such as "Modern Control Theory", "Computer Control System", "Optimal Control", "Process Control" as well as "Adaptive Control". It plays an important role in the students' curriculum and is listed as the graduate entrance examination course. This course features rich content, strong theory, a wide range of knowledge and more abstract characteristics. It has a certain depth and learning difficulty [5-6]. In the complete credit system, number of teaching hours and audiences in the class has changed. Students may come from different majors and different grades. The number of teaching hours is also dropped from 80 class hours to 64 class hours.

Reforms of teaching method and assessment strategies are presented in Section 3. Conclusion is given in section 4.

Table 1 Class hour's distribution for each chapter

\begin{tabular}{|l|l|l|}
\hline Contents & $\begin{array}{l}\text { Hours (80 } \\
\text { in total) }\end{array}$ & $\begin{array}{l}\text { Hours (64 } \\
\text { in total) }\end{array}$ \\
\hline Chapter 1 Introduction & $1-2$ & 1 \\
\hline $\begin{array}{l}\text { Chapter 2 System } \\
\text { modeling }\end{array}$ & $3-17$ & $2-15$ \\
\hline $\begin{array}{l}\text { Chapter 3 Time domain } \\
\text { analysis of linear system }\end{array}$ & $18-34$ & $16-29$ \\
\hline $\begin{array}{l}\text { Chapter 4 Root locus } \\
\text { analysis }\end{array}$ & $35-50$ & $30-42$ \\
\hline $\begin{array}{l}\text { Chapter 5 Frequency } \\
\text { response domain }\end{array}$ & $51-67$ & $43-54$ \\
\hline $\begin{array}{l}\text { Chapter 6 Design and } \\
\text { correction of control } \\
\text { systems }\end{array}$ & $58-80$ & $55-64$ \\
\hline
\end{tabular}

\section{SETUP PREREQUISITES FOR COURSE SELECTION}

2.1 Setup Restrictions for Course Attendance

In the academic year credit system, students begin to study "Automatic Control Theory" in the junior semester according to the procedure prescribed by teaching plan. The students in the class are a natural class and they had 
Vol. 3, Issue 11, November 2016

finished learning exactly the same courses although their levels of understanding the key knowledge are inconsistent. But in complete credit system, students can choose their courses according to their learning ability. Therefore, students in the class will include freshman, sophomore, junior, senior ones. Some students want to prepare for the entrance exam of graduate, so they may learn the course in advance. However, "Automatic Control Theory" is a basic course with strong theory. Before studying this course, students need to have some basic knowledge. Otherwise, they will feel like 'on the plane' while sitting on the classroom and cannot understand anything, which will lead to poor study effect. The Prerequisite of learning "Automatic Control Theory" is that students must finish studying "Advanced Mathematics", "Circuit", "Analog Electronic Technology", "College Physics", "Complex Function and Integral Transformation" and etc. It is because when deriving transfer function of electrical network composed of resistors, capacitors, inductors, motors, operational amplifiers and other components or deriving the transfer function of mechanical systems, the integral operation and Laplace transform, Kirchhoff Current - Voltage Law and Newton's second law will be used. Thus, students cannot select the course by their wiliness and should still follow the gradual and orderly teaching law.

According to the above mentioned, in the teaching management system, it is necessary to set certain restrictions for students enrolled in the course. Only those students who has finished the above basic courses and achieved good examination results have the permissions to access course selection system and can select to attend "automatic control theory" course successfully.

2.2 Set student number restrictions in one class and open more classes for selection

As we know from the teaching practice over 10 years, the learning outcome in a small class of 30 students would be better than that in a large class of 60 or more students. In complete credit system, students meeting the course selection prerequisites are free to choose their favorite teacher. In our university, there are 3-4 teachers who are engaged in teaching "Automatic Control Theory" course. Therefore, there may be a very large number of students under the name of one teacher, far beyond the number of students in a normal class. In response to this situation, it is recommended that the number of students under a teacher should be limited (for example, 35) in teaching management system. If the number is greater than that limit, a new class will be automatically created and students can still attend the course taught by their favorite teacher except that it would be taught at different times and places. This will truly reflect the nature of completer credit system, rather than students can only select the course taught by teachers they do not like when students number exceed the limitation. Excellent teachers can have more than one class and some unpopular teachers may not commence due to insufficient number of students. By this way, it forms a competition among teachers on the teaching so that it urges teachers to work hard to prepare for lessons and promote upgrading of teaching quality.

\section{REFORMS OF TEACHING METHOD AND ASSESSMENT STRATEGIES}

3.1 Strengthen feedback between teachers and students and highlight learning emphasis

"Automatic control theory" is a strong theoretical course, involving a broad theoretical base, including advanced mathematics, linear algebra, complex function, physics and circuits and etc. Some students often feel difficulty in learning this course and have a greater psychological burden. Therefore, prior to the course learning, teachers should fully aware of the content relationship between this course and the other courses. In the class, teachers should communicate with students and understand the basic knowledge preparation of students[7-8]. According to the feedback from students, teachers should help students to review the relevant math and other key basic knowledge points at an appropriate time. For example, when beginning to explain the "transfer function" of Chapter 2, teachers should ask students some questions about Laplace transforms and inverse transformations, and arrange for a relevant short review based on student feedback to help students to accept new knowledge points more smoothly.

In addition, taking into account the uneven theoretical basis of students, teachers in class should try to focusing on analysis of knowledge that students feel difficult to understand. Some students may get the idea faster while others may still confused because of poor learning ability. So teachers should take a little time to review the contents of the last class before each new lesson, and randomly select students to answer questions so as to check students learning results. In this way, it can urge students to review what they learn in a timely manner, on the other hand it also give some time for students to deepen their understanding. Before starting each new chapter, teachers should highlight the learning priorities and requirements of this chapter on the blackboard with a conspicuous symbolic emphasis on what points must be mastered and what is knowledgeable. When ending a chapter, teachers should reaffirm the emphasis, so that students will be targeted, focused, thus improve learning outcomes.

\subsection{Proper Use Blackboard Writing and Multimedia Teaching Methods}

Multimedia teaching methods have been very popular in our university and most of the classrooms are equipped with a projector. But not all courses and all the knowledge points are suitable for use of multimedia teaching methods. According to teaching experience, part of content in automatic control theory course is very suitable for use of multimedia teaching methods[9-10]. For example, when teaching "root locus law" and "frequency method" lessons, teachers can use multimedia PPT to visualize and demonstrate root locus graphics drawing 
quickly and leave more time to focus on analysis control system performance by root locus graphics. PPT demonstration can makes the lesson vivid and focused while the traditional blackboard writing will waste a lot of classroom time on drawing, and drawing is also difficult to be accurate. It will even lead students to draw graphics without really understand its meaning and usage. However, when formula derivation is need in classroom, it is not recommend to use multimedia teaching methods, on the contrary, the traditional blackboard teaching will be more suitable to guide students step by step and get better learning results.

\subsection{Carefully Select Examples \& Exercises and Combine Theory with Practice}

As to the examples and exercises selection, it is not the same as high school to use "plentiful exercises tactics ". Teachers should choose some representative, typical examples to explain. A question will have a variety of solutions, so teachers should encourage students to develop problem-solving ideas to use different knowledge in different chapters so as to digest completely what they have learned. For example, when explaining the equivalent transformation of control system structure block diagram, after illustrating an equivalent transformation, teachers can ask students to consider whether there are other equivalent transformations to derive the system transfer function and encourage students to use branch points go to previous /next, sum points go to previous /next to make a try.

Sometimes, a problem can have 6 kinds of solutions, so though an example, students can master the basic methods of transforming the system block diagram and summarize in what case which solution is more simple and fast. When judging the stability of control system, we can use the knowledge points introduced in Chapter 3 (such as Routh Criterion), Chapter 4 (such as root locus method) or Chapter 5 (such as Nyquist Stability Criterion). When ending lessons in each chapter, according to the student's exercises feedback, teachers should arrange an exercise explain lesson, focus on the existing problems among students and help them to solve the learning confusion.

\subsection{Create Course Online Site and Provide Online Questions and Answers}

It is recommended to create course online website, which is open to the public on the network[11]. The specific teaching materials including the syllabus, teaching plan, experimental syllabus, experimental instruction, teaching notes, PPT, video on difficult and key knowledge points, references should be uploaded to the network for students to browse, read, learn and download.

Due to the implementation of the complete credit system, teachers will face students from different grades, different majors and different academic schools. Students are not familiar with each other so the management of students more difficult. For this reason, an electronic attendance system should be created in the website with permissions for student accounts and teacher accounts. Student accounts have the permission to the following activities such as experimental courses preview, problem consultation, course content download and self-learning as well as online chapter test. Teacher can use their accounts to $\log$ on the system to check students attendance, experiment preparation and test results, answer students questions so as to strengthen the communication between teachers and students. They can discuss learning experiences, share learning methods and skills thus improve students' learning outcomes. Though the hyperlink of each student name, teachers can get student contact information such as student's phone numbers, their counselor phone number, and their parents' phone number. Once a student attendance is very low, teacher can use a variety of ways in time contact student, communicate with him and urge him to back to class.

\subsection{Change Assessment Strategies}

Assessment is an important way to evaluate students' learning outcome. The assessment results have a very important role in regulating students to choose teachers and learning initiatives. Strict uniform assessment will help to avoid students in selecting of poorly managed and demanding teachers while avoiding choosing rigorous and demanding teachers. Students are strictly forbidden to select teachers just out of the purposes of passing the course assessment.

The initial assessment method mainly depends on the students' final exam result. But it is difficult to fully test students' understanding of the relevant concepts and knowledge. It is also very hard to evaluate how well students master the necessary methods of analyzing and designing actual control systems only based on two hours examination. For this reason, we change the assessment strategies. The final grade score adds the usual attendance, classroom interaction performance, homework performance and experimental operation performance. Final exam accounted for $60 \%$, classroom attendance $10 \%$, classroom interaction performance $10 \%$, homework performance $10 \%$ and experiment operation and experimental report $10 \%$. The questions in the final exam will take diverse form of different difficulty to avoid part of the students to apply the formula directly without the ability to analyze and solve problems.

\section{CONCLUSIONS}

This paper explores some practices of how to improve the teaching quality of automatic control theory in complete credit system. The course of "automatic control theory" is a course strong in theory and concept, so it is very difficult for students to learn and master. In this paper, from the viewpoint of course selection restrictions, teaching methods and assessment strategies, we summarize some of the experiences in the teaching process over the years. Of course, there are many other ways to promote the improvement of teaching quality, teachers need to 
continually learn new teaching theories, explore new teaching methods and use flipped classroom to promote students' learning outcomes.

\section{ACKNOWLEDGMENT}

This work is supported by the Education Reform Funds of Shanghai University of Engineering Science under No. K201502001 and No.p201602001.

\section{REFERENCES}

[1] Cheng Weixing, Li Caiyun. The New Tactics of Constructing Academic Atmosphere under Complete Credit System, Meitan Higher Education, Vol. 27,No.4, 2009,pp. 69-70.

[2] Zhong Liping, Luo Ting. The Problems and Countermeasures of College Curriculum Management under Complete Credit System , Higher Education Development and Evaluation, Vol. 3,No.23, 2007,pp.108-112.

[3] Li Xiaoguang, Du Yi. Construction of Complete Credit System and Curriculum Center Platform, Higher Education Forum, Vol.3, 2013 pp.15-16.

[4] JIA Changyun, Liu changing, Li jiming. Exploration into the Problems in Process Management of Human-oriented Complete Credit System, Journal of Huaihai Institute of Technology(Social Science Edition), Vol.8,No.8, 2010,pp.1-4.

[5] LI Changyun. Teaching Practice of Automatic Control Theory with Systemic View, Journal of EEE, Vol.35,No.4, 2013,pp.75-77.

[6] Liao shouyi, zhang hexin, Zhang guoliang. Exploration and Practice of Effective Teaching Methods for Automatic Control Theory, China Modern Educational Equipment, Vol.11, 2012,pp.60-62.

[7] ZHANG Xiuling, LIU Zhixin, MA Hui. Research on Teach Reform and Practice of Automation Control Theory Quality Course based on CDIO Mind, Research in Teaching, Vol.3, 2012,pp.41-43.

[8] ZHOU Wuneng, SHI Hongrui. Teaching innovation and practice for course of Automatic Control Principle, Research in Teaching, Vol.33, No.1, 2010, pp.63-66.

[9] ZHANG Yu-ye. Details Teaching of Automatic Control Theory Course, Journal of Electrical \& Electronic Education, Vol.36, No.3, 2014, pp.67-70.

[10] WU Yuanyuan, LI Qingbo On the Automatic Control Theory Teaching Reform, The Guide of Science \& Education, Vol.4, 2014, pp.146-147.

[11] Chen Pan. Analysis of Teaching Methods for Principles of Automatic Control, The Science Education Article Cultures, Vol.35, 2015, pp.51-52. 